break of hostilities in 1939 he was commissioned in the survey branch of the Royal Engineers, and he was among those evacuated from Dunkirk. Following a period of service in England he was posted to Italy and was in charge of the map production branch of the Survey Directorate. At the end of the War he returned to his post at King's College, Newcastle, but shortly afterwards was appointed to the staff of the Department of Geography at Cambridge. When the University of Leeds created an additional chair of geography, Prof. Peel was appointed to fill it and on the retirement of Prof. A. V. Williamson he became head of the Department. While at Leeds, in addition to obtaining and occupying new premises, Prof. Peel has visited East Africa and Canada, and sustained his interest in problems of the physical geography of northern England. His teaching and research interests are not, however, narrowly confined, and in the Bristol environment he will find satisfaction in the developments there in surveying and cartography, as well as in physical and human geography.

\section{Second Geneva Conference on Peaceful Uses of Atomic Energy}

THE second International Conference on the Peaceful Uses of Atomic Energy is to be held in Geneva during September 1-13, 1958. A provisional agenda has been agreed by the seven-nation Advisory Committee, of which Sir John Cockcroft is the member for the United Kingdom, providing for twelve plenary sessions embodying papers of a general survey type, and four parallel series of technical sessions covering the following subjects: Series 1 : chemistry and the chemical processing of irradiated fuel, reactor technology, radiation damage in reactor materials, handling of highly irradiated materials, treatment of radioactive wastes; Series 2: nuclear physics including the physies of fission and fusion reactors, reactor theory, fuel cycles and the economics of nuclear power, research, test and prototype power reactors, reactor experiments ; Series 3 : production and uses of isotopes and ionizing radiations in research, medicine, agriculture and industry, dosimetry, biological effects of radiation, radiological protection, reactor safety and location, meteorological and oceanographical aspects of the largescale use of atomic energy ; Series 4 : raw material supplies, winning and refining of uranium and thorium, methods of separation of isotopes, metallurgy and fabrication of fuel elements, processing of other nuclear materials.

The Conference will be conducted under the same rules of procedure as in 1955 , which are published as Annex 2 in Vol. 16 of the Proceedings of the International Conference on the Peaceful Uses of Atomic Energy. Officials of the Conference, including the president, secretary-general and chairmen of the technical sessions, will be announced later. Arrangements for participation by the United Kingdom are being organized through an Executive Committee (chairman, Sir John Cockeroft ; secretary, Mr. B. W. Mott) and a Papers Committee (chairman, Dr. B. F. J. Schonland; secretary, Dr. T. A. Hall) on which are representatives of the U.K. Atomic Energy Authority, the Central Electricity Authority, industry, universities and other bodies. Titles and 500word abstracts of papers must be in the hands of the secretary-general of the United Nations by March 1, 1958, and final texts by June 1, 1958. At present the Papers Committee is engaged on the compilation of a provisional list of titles, with the object of estimating the number of papers likely to be submitted from the United Kingdom and their distribution between the various sessions. It is hoped that this information will be available by September 1, 1957. Organizations represented on the Papers Committee will be approached by their representatives for contributions, but others should communicate directly with the Papers Secretary, at the Atomic Energy Research Establishment, Harwell, Berkshire, if they have titles to submit or if they require further information. Inquiries concerning matters other than the submission of papers should be addressed to the Secretary of the Executive Committee, at the same address.

\section{U.S. National Science Foundation Research Grant for Aslib}

THE United States National Science Foundation has made an award of $£ 10,000$ to Aslib for research into the comparative efficiency of various indexing and literature search systems. The research programme, which is expected to take two years, is to be conducted at the College of Aeronautics, Cranfield, under the direction of Mr. C. W. Cleverdon, librarian of the College. Many new techniques have been evolved in recent years in an effort to overcome the problems created by the vastly greater flow of research papers and the increased need to locate information due to the growing complexity and volume of scientific and industrial research. The research which has been planned is intended to provide evidence as to whether and in what circumstances one indexing system is more efficient than another. First, some 20,000 research reports on aeronautical engineering matters will be indexed under five different systems. Strict controls, covering time and other relevant economic factors, will be maintained at all stages of the work. When this has been completed, it is intended to carry out exhaustive tests on the indexes in order to show their comparative efficiency in varying conditions.

\section{Journal of Electronics and Control}

StaRTING in July with the first number of Vol. 3, the Journal of Electronics will contain an additional section dealing with control systems and mechanisms and its title will be changed to Journal of Electronics and Control. The Electronics Section will continue to publish papers devoted to all aspects of electron science as heretofore, and the new control section, which will be the responsibility of the recently appointed assistant editor, Mr. J. R. Day, will consist of contributions on any aspect of the science of control, either fundamental or arising in the context of industrial or other problems. The principles of detection and measurement, process control, the control of electrical and mechanical quantities in the field of servo-systems, the applications of electronic devices to control systems, and the automatic handling of data come within its purview, but not the study of organizational, economic and psychological factors involved in control engineering. Space will still be reserved in each number for book reviews, news items and correspondence. The number of pages will be increased from 100 to 130 , and for the time being the frequency of publication of the Journal will remain unchanged-six parts per annual volume. There will be no increase in the annual subscription rate or in the price per single copy. 